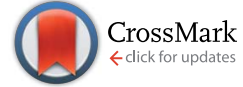

Cite this: Chem. Sci., 2014, 5, 4906

\title{
Cobalt sulphide microtube array as cathode in photoelectrochemical water splitting with photoanodes $\uparrow$
}

\author{
Chia-Yu Lin, \$ Dirk Mersch, David A. Jefferson and Erwin Reisner*
}

We report on a cobalt sulphide (COS) electrode prepared by simple and scalable chemical bath deposition (CBD), which performs as a highly efficient and robust electrocatalyst for the $\mathrm{H}_{2}$ evolution reaction (HER) in both neutral and $\mathrm{pH} 13$ electrolyte solution at a small overpotential $(\eta<90 \mathrm{mV}$ ). At $\eta=390 \mathrm{mV}$, turnover frequencies of $38.8 \pm 1.9$ and $52.1 \pm 2.0 \mathrm{~mol} \mathrm{H}_{2}(\mathrm{~mol} \mathrm{Co})^{-1} \mathrm{~h}^{-1}$ were achieved with high stability (Faradaic efficiency $>95 \%$ for at least $72 \mathrm{~h}$ ) and turnover numbers of approximately 2600 and 3400 in neutral and basic electrolyte solution, respectively. The rate of HER per geometric area is further enhanced by employing a CoS microtube array (microCoS), which is prepared by sulphurisation of a cobalt hydroxide carbonate nanorod array template using CBD. MicroCoS shows excellent HER activity when it is coupled with a cadmium sulphide sensitised zinc oxide photoanode in the presence of sodium sulphide and a nanostructured hematite $\left(\alpha-\mathrm{Fe}_{2} \mathrm{O}_{3}\right)$ photoanode from photoelectrochemical water splitting in basic electrolyte solution.

Received 18th June 2014

Accepted 15th August 2014

DOI: $10.1039 / \mathrm{c} 4 \mathrm{sc} 01811 \mathrm{~g}$

www.rsc.org/chemicalscience

challenge, and there is an urgent need for a scalable and inex-

\section{Introduction}

Photoelectrochemical (PEC) water splitting is a promising approach to convert intermittent sunlight into a storable and renewable chemical fuel, $\mathrm{H}_{2}{ }^{1}$ The success of clean water splitting systems will not only rely on the development of a device consisting of robust, efficient, inexpensive, and environmentally benign components, but also on the compatibility of the catalysts and light absorbers in an integrated system. The earthabundant light absorbers ${ }^{2}$ and water oxidation electrocatalysts ${ }^{3}$ developed so far are mainly functional in neutral or basic conditions, whereas most non-noble metal-based $\mathrm{H}_{2}$ evolution electrocatalysts $\left(\mathrm{H}_{2} \text {-cats }\right)^{4}$ require acidic conditions. Although some inexpensive electrocatalysts, such as molybdenum boride/ carbide, ${ }^{5}$ metal nitrides, ${ }^{4 f}$ have been reported as promising $\mathrm{H}_{2}$ cats at room temperature in alkaline solution, their preparation often involves costly and energy-intensive processes, ${ }^{4 f}$ which makes large-scale production and their integration into the photoelectrodes difficult. As a result, the development of an inexpensive, robust and highly efficient electrocatalyst pair, which operates under the same condition, is an essential

Christian Doppler Laboratory for Sustainable SynGas Chemistry, Department of Chemistry, University of Cambridge, Lensfield Road, Cambridge CB2 1EW, UK. E-mail: reisner@ch.cam.ac.uk

$\dagger$ Electronic supplementary information (ESI) available: Experimental details, crystallographic data and spectral data. See DOI: 10.1039/c4sc01811g

\$ Current address: Department of Chemical Engineering, National Cheng Kung University, 1 University Road, Tainan City 70101, Taiwan. pensive $\mathrm{H}_{2}$-cat that operates at $\mathrm{pH} \geq 7$.

Cobalt based $\mathrm{H}_{2}$-cats, including metallic $\mathrm{Co}^{6}$ and molecular Co complexes, ${ }^{7}$ have been proposed as alternative electrocatalysts to noble metals for the hydrogen evolution reaction (HER). However, the requirement of a high overpotential to achieve a reasonable $\mathrm{H}_{2}$ evolution rate in neutral aqueous electrolyte solution or poor stability is an unsolved problem. Recently, a HER catalyst $\left(\mathrm{H}_{2}\right.$-CoCat) composed of metallic cobalt nanoparticles with a cobalt-oxo/hydroxo-phosphate layer was prepared by prolonged electrodeposition of a cobalt salt in phosphate buffer. ${ }^{8}$ The $\mathrm{H}_{2}$-CoCat shows considerably higher activity than metallic cobalt in a pH neutral electrolyte solution (TOF of $\mathrm{H}_{2}$-CoCat $\sim 80 \mathrm{~h}^{-1}$ at $\eta$ of $385 \mathrm{mV}$ at $\left.\mathrm{pH} 7\right),{ }^{8}$ and to further explore $\mathrm{H}_{2}$-cats with better HER activity, we therefore decided to explore the HER activity of different cobalt species. Recently, cobalt sulphide has been explored as an effective electrocatalyst for the reduction of tri-iodide, ${ }^{9}$ poly sulphide, ${ }^{\mathbf{1 0}}$ and oxygen. ${ }^{\mathbf{1 1}}$ However, as compared with other metal sulphides, ${ }^{\mathbf{4 a - e , 1 2}}$ the application of cobalt sulphide to HER received little attention, ${ }^{4 d, 13}$ which can be attributed to the facts that studies have often been carried out under strongly acidic conditions, where cobalt sulphide is prone to dissolution and generation of $\mathrm{H}_{2} \mathrm{~S}$.

In this study, the HER activity of cobalt sulphide (CoS), prepared by a simple and scalable chemical bath deposition (CBD) method, was thoroughly investigated under neutral and basic conditions. Subsequently, a CoS microtube array was prepared using CBD to further increase the $\mathrm{H}_{2}$ evolution rate per geometric surface area. Finally, we demonstrate that microCoS can be employed as a cathode in efficient PEC water 
splitting systems, where the use of alkaline electrolyte is often indispensable.

\section{Experimental section}

\section{General considerations}

Starting materials for the synthetic part of the work were purchased from commercial suppliers and of the highest available purity for the analytical work. Flouride-doped tin oxide (FTO) coated glass (sheet resistance $7 \mathrm{ohm} \mathrm{sq}^{-1}$, TEC Glass ${ }^{\mathrm{TM}} 7$ ) substrates $\left(1.0 \times 3.0 \mathrm{~cm}^{2}\right)$ were cleaned with an ammoniahydrogen peroxide-deionised water mixture (volume ratio: $1: 1: 5$ ) at $70^{\circ} \mathrm{C}$ for $20 \mathrm{~min}$, followed by sonication in water for $15 \mathrm{~min}$ and drying at room temperature.

\section{Preparation of $\mathrm{CoS}, \mathrm{Co}_{3} \mathrm{O}_{4}$, and $\mathrm{Co}_{9} \mathrm{~S}_{8}$ electrodes}

$\mathrm{CoS}$ was deposited onto the FTO substrate (exposed area of $\left.2.0 \mathrm{~cm}^{2}\right)$ with epoxy tape $(0.14 \mathrm{~mm}$ thickness) as spacer by using chemical bath deposition (CBD) in an aqueous solution $(10 \mathrm{~mL})$ containing urea $(50 \mathrm{mM}), \mathrm{CoCl}_{2} \cdot 6 \mathrm{H}_{2} \mathrm{O}(50 \mathrm{mM})$, and thioacetamide $(0.1 \mathrm{M})$ at $90{ }^{\circ} \mathrm{C}$ for $4 \mathrm{~h}$. The obtained electrode, designated as $\mathrm{FTO} \mid \mathrm{CoS}$, was rinsed with water and dried at room temperature. To prepare $\mathrm{FTO} \mid \mathrm{Co}_{3} \mathrm{O}_{4}$ and $\mathrm{FTO}\left|\mathrm{Co}_{9} \mathrm{~S}_{8}, \mathrm{FTO}\right|$ $\mathrm{CoS}$ was annealed in air and nitrogen at $500{ }^{\circ} \mathrm{C}$ for $2 \mathrm{~h}$, respectively. The film thickness of $\mathrm{Co}_{3} \mathrm{O}_{4}, \mathrm{Co}_{9} \mathrm{~S}_{8}$, and $\mathrm{CoS}$ is approximately $150 \mathrm{~nm}$. The amount of cobalt species on these electrodes was determined by UV-vis spectrophotometry $\left(0.59 \mu \mathrm{mol} \mathrm{cm}^{-2}\right.$, vide infra $)$.

\section{Preparation of $\mathrm{Co}(\mathrm{OH})_{2}$ electrode}

$\alpha$ - $\mathrm{Co}(\mathrm{OH})_{2}$ plates, with average film thickness of $\sim 5 \mu \mathrm{m}$, was deposited onto the FTO substrate (exposed area of $2.0 \mathrm{~cm}^{2}$ ) using $\mathrm{CBD}$ in an aqueous solution $(10 \mathrm{~mL})$ containing $\mathrm{CoCl}_{2} \cdot 6 \mathrm{H}_{2} \mathrm{O}$ $(50 \mathrm{mM})$ and hexamethylenetetramine $(0.1 \mathrm{M})$ at $90^{\circ} \mathrm{C}$ for $4 \mathrm{~h}$. The amount of cobalt species was determined by UV-vis spectrophotometry $\left(2.25 \mu \mathrm{mol} \mathrm{cm}^{-2}\right.$, vide infra $)$. The obtained electrode, designated as $\mathrm{FTO} \mid \mathrm{Co}(\mathrm{OH})_{2}$ electrode, was rinsed with water and dried at room temperature.

\section{Preparation of metallic Co electrode}

Electro-deposition of metallic cobalt was carried out following a published procedure. ${ }^{14}$ Briefly, metallic cobalt $(\sim 0.5 \mu \mathrm{m})$ was electrodeposited onto the FTO substrate (exposed area of $\left.1.0 \mathrm{~cm}^{2}\right)$ from an aqueous solution $(20 \mathrm{~mL}, \mathrm{pH} 4.6)$ containing ammonium chloride $(1 \mathrm{M})$ and $\mathrm{CoCl}_{2} \cdot 6 \mathrm{H}_{2} \mathrm{O}(0.01 \mathrm{M})$ at $-1.0 \mathrm{~V}$ vs. $\mathrm{Ag} / \mathrm{AgCl}$ for $5 \mathrm{~min}$. The averaged charge passed is $0.68 \mathrm{C}$ $\mathrm{cm}^{-2}$. The amount of metallic cobalt was determined, by UV-vis spectrophotometry $\left(1.59 \mu \mathrm{mol} \mathrm{cm}{ }^{-2}\right.$, vide infra $)$, corresponding to a Faradaic efficiency of $45 \%$. The obtained electrode, designated as FTO|Co electrode, was rinsed with water and dried at room temperature.

\section{Preparation of FTO|microCoS}

CoS microtubes (with closed end) were grown on an FTO substrate by first growing layered hydroxide cobalt carbonate acicular nanorods (FTO|nanoLHCC), followed by the conversion of FTO|nanoLHCC into FTO|microCoS under CBD conditions. The FTO|nanoLHCC electrode was prepared following a previously reported procedure. ${ }^{15}$ The conversion of FTO|nanoLHCC into FTO $\mid$ micro CoS was achieved by immersing FTO|nanoLHCC into a bath solution containing urea $(50 \mathrm{mM}), \mathrm{CoCl}_{2} \cdot 6 \mathrm{H}_{2} \mathrm{O}$ $(50 \mathrm{mM})$, and thioacetamide $(0.1 \mathrm{M})$ at $90{ }^{\circ} \mathrm{C}$ for $6 \mathrm{~h}$.

\section{Preparation of FTO|nanoZnO| $\mathrm{CdS}_{\mathrm{NP}}$}

This electrode consists of cadmium sulphide nanoparticles $\left(\mathrm{CdS}_{\mathrm{NP}}\right.$ )-sensitised $\mathrm{ZnO}$ nanosheets (nanoZnO) on an FTO substrate. Firstly, layered hydroxide zinc carbonate nanosheets (nanoLHZC), $\sim 15 \mu \mathrm{m}$ in thickness, were grown on the FTO substrate $\left(2.0 \mathrm{~cm}^{2}\right)$ with epoxy tape as spacer by using CBD in a solution containing urea (16.7 wt\%) and zinc nitrate hexahydrate $(0.15 \mathrm{M})$ at $90^{\circ} \mathrm{C}$ for $4 \mathrm{~h}$, followed by thermal conversion of nanoLHZC into nanoZnO at $300{ }^{\circ} \mathrm{C}$ in air for $30 \mathrm{~min} .{ }^{16}$ The sensitisation of nanoZnO with $\mathrm{CdS}_{\mathrm{NP}}$ was achieved by using a procedure reported elsewhere. ${ }^{17}$ Briefly, the FTO|nanoZnO electrode (exposed area of $2.0 \mathrm{~cm}^{2}$ ) was immersed into a solution $(10 \mathrm{~mL})$ containing cadmium chloride $(10 \mathrm{mM})$ and thioacetamide $(10 \mathrm{mM})$ at room temperature for $90 \mathrm{~min}$. Finally, the obtained electrode was rinsed with water and dried at room temperature.

\section{Preparation of FTO|nanoFe ${ }_{2} \mathrm{O}_{3}$}

To prepare a tin doped $\alpha-\mathrm{Fe}_{2} \mathrm{O}_{3}$ nanorod electrode (FTO| nanoFe ${ }_{2} \mathrm{O}_{3}$ ), $\beta$-FeOOH nanorods, with $\sim 600 \mathrm{~nm}$ in length and $\sim 50 \mathrm{~nm}$ in diameter, were firstly grown onto the FTO substrate $\left(2.0 \mathrm{~cm}^{2}\right)$ with epoxy tape as spacer by using CBD in a bath solution containing iron chloride hexahydrate $(0.15 \mathrm{M})$ and urea (6.25 wt\%) at $90{ }^{\circ} \mathrm{C}$ for $4 \mathrm{~h}$. Thereafter, $20 \mu \mathrm{L}$ of $20 \mathrm{mM} \mathrm{SnCl}_{4}$ ethanolic solution was drop-coated onto the $\beta$-FeOOH nanorods three times, followed by annealing at $750{ }^{\circ} \mathrm{C}$ for $30 \mathrm{~min}$. Note that, to remove the excess $\mathrm{SnO}_{2}$, the annealed electrodes are treated in $1 \mathrm{M} \mathrm{NaOH}$ at room temperature for $12 \mathrm{~h}^{18}$

\section{Physical characterisation}

The surface morphology of the electrodes was characterised using a Phillips XL30-SFGE and a Hitachi SU-8010 scanning electron microscope (SEM). The nanoscale images of the microCoS tubes were obtained using a JEOL 3011 high resolution transmission electron microscope (HR-TEM) with samples made by scratching the film off the FTO substrate and dispersing the powder in acetone under ultrasonication for 5 min. X-ray diffraction (XRD) analyses were carried out using an X'Pert PRO (PANalytical B.V., The Netherlands) and an Ultima IV (Rigaku Co., Japan) X-ray diffractometer. To determine the amount of cobalt on the electrode, these cobalt species were dissolved to form $\left[\mathrm{CoCl}_{4}\right]^{2-}$ complex ions by ultrasonicating the electrodes (exposed area of $2 \mathrm{~cm}^{2}$ ) in a concentrated $\mathrm{HCl}$ solution $(12 \mathrm{~N}, 10 \mathrm{~mL})$ for $20 \mathrm{~min}$. $\left[\mathrm{CoCl}_{4}\right]^{2-}$ ions were quantified by measuring the absorbance at $624 \mathrm{~nm}$ using a calibration curve of absorbance at $624 \mathrm{~nm} v$ s. concentration of $\left[\mathrm{CoCl}_{4}\right]^{2-}$. The surface composition of the films was verified by X-ray photoelectron spectroscopy (XPS, PHI 5000 VersaProbe system, 
ULVAC-PHI, Chigasaki, Japan), using a microfocused (100 $\mu \mathrm{m}$, $25 \mathrm{~W}) \mathrm{Al}$ X-ray beam, with a photoelectron take off angle of $45^{\circ}$. The Ar ion source for XPS (FIG-5CE) was controlled by using a floating voltage of $0.2 \mathrm{kV}$. The binding energies obtained in the XPS analyses were corrected for specimen charging, by referencing the $\mathrm{C} 1 \mathrm{~s}$ peak to $285.0 \mathrm{eV}$.

\section{Electrochemical and PEC measurements}

Electrochemical experiments were performed with an Ivium CompactStat (Ivium Technologies B.V.) and an Autolab PGSTAT204 (Eco Chemie B.V.) at $25{ }^{\circ} \mathrm{C}$ and all potentials are reported against the reversible hydrogen electrode (RHE) by using the equation $E(\mathrm{~V} v s$. RHE $)=E(\mathrm{~V} v s$. $\mathrm{Ag} / \mathrm{AgCl})+0.197+$ $0.059 \times \mathrm{pH}^{2 e}$ A conventional one-compartment three-electrode electrochemical cell was employed for linear sweep voltammetry (LSV) unless otherwise noted; FTO|CoS, FTO|CoS, FTO| $\mathrm{Co}(\mathrm{OH})_{2}, \mathrm{FTO} \mid \mathrm{Co}_{3} \mathrm{O}_{4}$, or FTO|Co was used as the working electrode connected to a $\mathrm{Pt}$ foil counter electrode and a $\mathrm{Ag} /$ $\mathrm{AgCl}_{\text {sat }}$ reference electrode. The electrocatalytic activity of the electrodes (all with exposed area of $1.0 \mathrm{~cm}^{2}$ ) was evaluated using LSV at a scan rate of $0.05 \mathrm{mV} \mathrm{s}^{-1}$ either in an aqueous $\mathrm{pH} 7$ solution containing triethanolamine (TEOA, $0.05 \mathrm{M}$ ) and sodium sulphate $(0.1 \mathrm{M})$, in an aqueous $\mathrm{pH} 13$ solution containing $\mathrm{KOH}(0.1 \mathrm{M})$ and sodium sulphate $(0.1 \mathrm{M})$, or in an another basic solution at $\mathrm{pH} 12.5$ with $\mathrm{Na}_{2} \mathrm{~S}(0.1 \mathrm{M})$ and TEOA $(0.05 \mathrm{M})$. Note that a TEOA buffer was used due to the irreversible oxidation of TEOA at the Pt counter electrode (preventing oxidation products to interfere with the reduction at the working electrode) and CoS is also stable in TEOA (in contrast to phosphate buffer; vide infra). When an aqueous basic electrolyte solution was used, the LSVs were carried out with three-electrodes in two-compartments separated by a Nafion ${ }^{\circledR} 117$ film (note the formation of $\mathrm{O}_{2}$ in the anodic compartment). It is noted that the electrolyte solution was prepared under $\mathrm{N}_{2}$ when $\mathrm{Na}_{2} \mathrm{~S}$ is used to avoid the possible formation of polysulphides.

Controlled-potential electrolyses with FTO|CoS, FTO|Co, FTO $\left|\mathrm{Co}(\mathrm{OH})_{2}, \mathrm{FTO}\right| \mathrm{Co}_{3} \mathrm{O}_{4}$, and $\mathrm{FTO} \mid \mathrm{Co}_{9} \mathrm{~S}_{8}$ working electrodes were performed at $\eta=390 \mathrm{mV}$ to allow for quantitative $\mathrm{H}_{2}$ detection (vide infra). Measurements at low $\eta$ resulted in correspondingly lower amounts of $\mathrm{H}_{2}$ produced and difficulty to determine the FE accurately.

PEC properties of FTO $\mid$ nanoFe ${ }_{2} \mathrm{O}_{3}$ and FTO $\mid$ nanoZnO $\mid \mathrm{CdS}_{\mathrm{NP}}$ (exposed area of $1.0 \mathrm{~cm}^{2}$ ) were examined in a two-compartment electrochemical cell with an aqueous basic electrolyte using LSV at a scan rate of $10 \mathrm{mV} \mathrm{s}^{-1}$ under illumination provided by a solar light simulator (Newport Oriel, $100 \mathrm{~mW} \mathrm{~cm}^{-2}$; calibrated with Newport High Power Detector equipped with a Newport 1916-R Handheld Optical Power Meter) equipped with an air mass 1.5 global filter and an IR water filter. FTO $\mid$ nano $\mathrm{Fe}_{2} \mathrm{O}_{3}$ or FTO| nanoZnO|CdS $_{\mathrm{NP}}$ was used as working electrode, whereas Pt foil or FTO|microCoS was used as counter electrode, and a Ag/ $\mathrm{AgCl}_{\text {sat }}$ reference electrode was employed during LSV. The $i-t$ transients and product measurements were carried out in a twoelectrode configuration (electrode separation: $\sim 10 \mathrm{~cm}$ ). A bias of $1.23 \mathrm{~V}$ was applied with the FTO|nano $\mathrm{Fe}_{2} \mathrm{O}_{3}$ based PEC water splitting system, whereas zero bias was applied with the

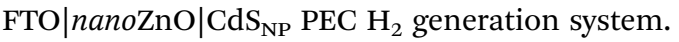

\section{Hydrogen and oxygen measurements}

The amount of $\mathrm{O}_{2}$ and $\mathrm{H}_{2}$ generated from the two-compartment two-electrode PEC systems was detected and quantified by headspace gas analysis with an Ocean Optics fluorescence $\mathrm{O}_{2}$ probe (FOSPOR-R) and an Agilent 7890A Series gas chromatography (GC) equipped with a $5 \AA$ molecular sieve column $\left(\mathrm{N}_{2}\right.$ carrier gas at a flow rate of approximately $3 \mathrm{~mL} \mathrm{~min}^{-1}$ ), respectively. The $\mathrm{O}_{2}$ probe was inserted in an anodic compartment through a tightly sealed septum and continuous $\mathrm{O}_{2}$ readings $\left(\mathrm{O}_{2}\right.$ partial pressure $)$ were recorded at $1 \mathrm{~s}$ intervals throughout the experiment. For $\mathrm{H}_{2}$ quantification, $20 \mu \mathrm{L}$ aliquots of the headspace gas were removed from the cathodic compartment of the PEC cell for GC analysis at the end of the experiment. The GC oven holding the columns was kept at $40{ }^{\circ} \mathrm{C}$, and a thermal conductivity detector was used. The twocompartment electrochemical cell was purged with $2 \% \mathrm{CH}_{4}$ in $\mathrm{N}_{2}$ (methane acts as internal standard for $\mathrm{H}_{2}$ quantification by GC). The two-electrode PEC cell was kept in the dark for $30 \mathrm{~min}$ (control experiment), followed by $2 \mathrm{~h}$ standardised solar light illumination $\left(100 \mathrm{~mW} \mathrm{~cm}^{-2}\right)$ and another $30 \mathrm{~min}$ in the dark.

\section{Results and discussion}

\section{Electrocatalytic HER activity of FTO|CoS thin film}

Coating of FTO with a thin film of CoS (FTO|CoS) was accomplished by CBD with $\mathrm{CoCl}_{2}$, urea and thioacetamide on FTOcoated glass in water at $90{ }^{\circ} \mathrm{C}$ for $4 \mathrm{~h}$. For comparison, other cobalt species, including $\mathrm{Co}(\mathrm{OH})_{2}, \mathrm{Co}_{3} \mathrm{O}_{4}$, metallic $\mathrm{Co}$, and $\mathrm{Co}_{9} \mathrm{~S}_{8}$ were also prepared (see Experimental section). Physical characterisations, including XRD and SEM, of these five cobalt species confirm the identity of the different Co species (Fig. S1 and $\mathrm{S} 2 \dagger)$. Fig. 1 shows LSV scans of the five cobalt species in a $\mathrm{pH}$ neutral electrolyte solution (50 mM TEOA and $0.1 \mathrm{M} \mathrm{Na}_{2} \mathrm{SO}_{4}$ ) at a scan rate of $0.05 \mathrm{mV} \mathrm{s}^{-1}$. The reduction of aqueous protons on FTO|CoS onsets at a relatively low overpotential $(\eta)$ of approximately $20 \mathrm{mV}$, which is comparable to FTO|Co. FTO|CoS shows a catalytic current density of $-1.0 \mathrm{~mA} \mathrm{~cm}^{-2}$ at an overpotential of $330 \mathrm{mV}$, which is only $120 \mathrm{mV}$ more cathodic than that of a Pt electrode (Fig. 1a). The overpotential requirement for FTO $\mid$ CoS to obtain $-1.0 \mathrm{~mA} \mathrm{~cm}^{-2}$ is lower than that for FTO| $\mathrm{Co}(\eta \sim 380 \mathrm{mV}), \mathrm{FTO} \mid \mathrm{Co}(\mathrm{OH})_{2}(\eta \sim 400 \mathrm{mV}), \mathrm{FTO} \mathrm{Co}_{3} \mathrm{O}_{4}(\eta \sim$ $450 \mathrm{mV}$; all data uncorrected for $i-R$ drop). $\mathrm{FTO} \mid \mathrm{Co}_{9} \mathrm{~S}_{8}$ exhibits the lowest electrocatalytic activity and $-0.45 \mathrm{~mA} \mathrm{~cm} \mathrm{~cm}^{-2}$ were observed at $\eta=450 \mathrm{mV}$. The difference in the HER activity of these cobalt species could be attributed to the difference in chemical composition, amount of Co loaded on the electrode, and surface morphology (see Fig. S2 $\dagger$ ). At this electrochemical screening stage, however, we only investigated the effects of chemical composition in more detail.

All cobalt species were subjected to $2 \mathrm{~h}$ electrolysis in $\mathrm{pH}$ neutral electrolyte solution. The chronoamperometric $(i-t)$ traces at various $\eta$ are shown in Fig. $1 \mathrm{~b}$ and $\mathrm{S} 3 \dagger$ the corresponding turnover frequency (TOF) and Faradaic efficiency (FE) 

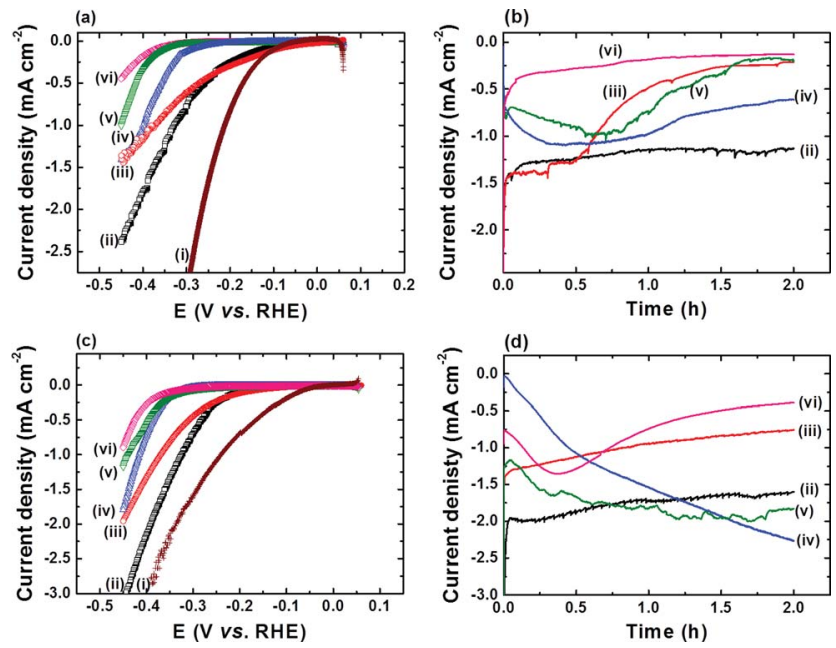

Fig. 1 Linear sweep voltammetry (LSV) scans, recorded at $0.05 \mathrm{mV} \mathrm{s}^{-1}$, of cobalt species in (a) $\mathrm{pH} 7$ and (c) pH 13 electrolyte solution (data not corrected for any uncompensated resistance losses). Chronoamperometric curves of the cobalt species at $\eta=390 \mathrm{mV}$ in (b) $\mathrm{pH} 7$ and (d) $\mathrm{pH} 13$ solution. The neutral $\mathrm{pH}$ contains TEOA $(50 \mathrm{mM})$ and $\mathrm{Na}_{2} \mathrm{SO}_{4}(0.1 \mathrm{M})$, whereas the $\mathrm{pH} 13$ solution contains $\mathrm{KOH}(0.1 \mathrm{M})$ and $\mathrm{Na}_{2} \mathrm{SO}_{4}(0.1 \mathrm{M})$ in water. Samples (i) to (vi) are Pt foil (brown), FTO|CoS (black), FTOlCo (red), FTOICo(OH) $)_{2}$ (blue), $\mathrm{FTO} \mathrm{CO}_{3} \mathrm{O}_{4}$ (green), and $\mathrm{FTO} \mathrm{Co}_{9} \mathrm{~S}_{8}$ (pink trace), respectively.

Table 1 Summary of the TOF and FE obtained from $\mathrm{H}_{2}$ measurements after $2 \mathrm{~h}$ controlled-potential electrolysis at $\eta=390 \mathrm{mV}$

\begin{tabular}{lrl}
\hline Sample & $\operatorname{TOF}^{c}\left(\mathrm{~h}^{-1}\right)$ & FE $(\%)$ \\
\hline $\mathbf{p H ~ 7 ^ { a }}$ & & \\
$\mathrm{CoS}^{d}$ & $38.8 \pm 1.9$ & $99.1 \pm 2.0$ \\
$\mathrm{Co}$ & $8.2 \pm 1.7$ & $91.8 \pm 2.5$ \\
$\mathrm{Co}(\mathrm{OH})_{2}$ & $6.8 \pm 0.9$ & $83.4 \pm 10.0$ \\
$\mathrm{Co}_{3} \mathrm{O}_{4}$ & $15.1 \pm 1.1$ & $82.1 \pm 1.0$ \\
$\mathrm{Co}_{9} \mathrm{~S}_{8}$ & $5.9 \pm 0.8$ & $72.6 \pm 2.3$
\end{tabular}

$\begin{array}{lr}\text { pH 13 } & \\ \mathrm{CoS}^{d} & \\ \mathrm{Co} & 52.1 \\ \mathrm{Co}(\mathrm{OH})_{2} & \pm 2.0 \\ \mathrm{Co}_{3} \mathrm{O}_{4} & \pm 1.5 \\ \mathrm{Co}_{9} \mathrm{~S}_{8} & 38.6 \pm 1.2 \\ \end{array}$

$96.3 \pm 3.7$ $92.0 \pm 8.4$ $75.5 \pm 1.2$

$74.6 \pm 3.8$ $74.4 \pm 4.2$

${ }^{a}$ TEOA $(0.05 \mathrm{M})$ and $\mathrm{Na}_{2} \mathrm{SO}_{4}(0.1 \mathrm{M}) .{ }^{b} \mathrm{KOH}(0.1 \mathrm{M})$ and $\mathrm{Na}_{2} \mathrm{SO}_{4}(0.1 \mathrm{M})$. ${ }^{c}$ Amount of Co was quantified by dissolving the film in concentrated $\mathrm{HCl}(\sim 12 \mathrm{M})$ and measuring the absorbance of $\left[\mathrm{CoCl}_{4}\right]^{2-}$ by UV-vis spectrophotometry. The TOF values were calculated taking all Co ions, including bulk Co, into account and are therefore an underestimated activity of these cobalt species. ${ }^{d}$ A TON of approximately 2600 with a FE of $96.2 \pm 2.8 \%$ was obtained at $\mathrm{pH} 7$ and a TON of $>3400$ with a FE of $94.1 \pm 4.8 \%$ after $72 \mathrm{~h}$ electrolysis at $\eta=390 \mathrm{mV}$ at $\mathrm{pH} 13$.

at $\eta=390 \mathrm{mV}$ in Table 1 . FTO $\mid \mathrm{CoS}$ showed the highest stability and activity: a TOF of $38.8 \pm 1.9 \mathrm{~h}^{-1}$ was reached after $2 \mathrm{~h}$ electrolysis and a turnover number (TON) of approximately 2600 with a FE of $96.2 \pm 2.8 \%$ was observed after $72 \mathrm{~h}$ electrolysis at $\eta=390 \mathrm{mV}$ (see Fig. S4 $\dagger$ ). FTO|Co showed a slightly lower catalytic onset potential than FTO|CoS, but it was unstable at $\eta>90 \mathrm{mV}$ with a lower TOF and FE after $2 \mathrm{~h}$ electrolysis at $\eta=$ $390 \mathrm{mV}$ (see Table 1 and Fig. 1). The initial $i-t$ transients of both FTO $\mid \mathrm{Co}(\mathrm{OH})_{2}$ and $\mathrm{FTO} \mid \mathrm{Co}_{3} \mathrm{O}_{4}$ at $\eta>90 \mathrm{mV}$ indicate low activity and accompanying electrochemical reaction processes (Fig. 1 and $\mathrm{S} 3 \dagger)$. Reduction of $\mathrm{Co}(\mathrm{OH})_{2}$ to metallic Co was reported to occur prior to HER, ${ }^{19}$ and we therefore suggest that the initial increase in cathodic current results from the reduction of $\mathrm{Co}(\mathrm{OH})_{2}$ to metallic Co, which accompanies HER. FTO|Co $\mathrm{CO}_{3} \mathrm{O}_{4}$ shows two regions with an increasing cathodic current, which might be assigned to the regions where the reductions of $\mathrm{Co}^{3+}$ to $\mathrm{Co}^{2+}$ and $\mathrm{Co}^{2+}$ to $\mathrm{Co}^{0}$ occur. ${ }^{20}$ These side reactions would further reduce the $\mathrm{FE}$ of $\mathrm{Co}_{3} \mathrm{O}_{4}$ and $\mathrm{Co}(\mathrm{OH})_{2}$ towards HER. In addition, we observed that the $\mathrm{Co}_{3} \mathrm{O}_{4}$ and $\mathrm{Co}(\mathrm{OH})_{2}$ films detached from the electrode during electrolysis, which can be attributed to the surface stress from structural changes induced by the electrochemical reduction processes during the electrolysis, and therefore, $\mathrm{Co}_{3} \mathrm{O}_{4}$ and $\mathrm{Co}(\mathrm{OH})_{2}$ are unstable and their corresponding HER activity is lower than FTO|CoS (Table 1).

Fig. 2 shows the XPS spectra of Co $2 p$ and $S 2 p$ for the FTO|CoS electrodes before and after $2 \mathrm{~h}$ controlled-potential electrolysis at various $\eta$. The Co $2 p$ and $S 2 p$ spectra display similar features for all measured samples. All Co $2 \mathrm{p}_{3 / 2}$ peaks appear at a binding energy of approximately $778.0 \mathrm{eV}$ with Co $2 \mathrm{p}_{3 / 2}-2 \mathrm{p}_{1 / 2}$ peak separation of $c a$. $15.0 \mathrm{eV}$ (Fig. 2a), which is typical for metallic Co or cobalt sulphide. ${ }^{21}$ The $S 2 p_{3 / 2}$ peaks at binding energy of approximately $161.8 \mathrm{eV}$, and $\mathrm{S} 2 \mathrm{p}_{3 / 2}$ and $2 \mathrm{p}_{1 / 2}$ doublet separation of $1.18 \mathrm{eV}$ (Fig. 2b), which corresponds to $\mathrm{S}^{2-}$ of CoS. ${ }^{21}$ The integration of the $S 2 p$ and Co $2 p_{3 / 2}$ peaks for samples (i) to (v) show that the loss of sulfur in CoS is minimal $(<20 \%)$ after $2 \mathrm{~h}$ controlledpotential electrolysis. In addition, in prolonged electrolysis (24 h electrolysis at $\eta=390 \mathrm{mV}$ ), FTO $\mid \mathrm{CoS}$ kept its crystalline structure (Fig. $\mathrm{S} 5 \dagger$ ). The results are in agreement with a previous report, where CoS decomposed only when the applied potential was more negative than $-1.0 \mathrm{~V}$ (vs. NHE, pH 6.1). ${ }^{22}$

Fig. 1c and d show the HER activity of all the cobalt species in basic electrolyte solution (0.1 M KOH and $0.1 \mathrm{M} \mathrm{Na}_{2} \mathrm{SO}_{4}$ at $\mathrm{pH}$ 13). The general trends are similar to $\mathrm{pH} 7$, and FTO|CoS shows the highest HER activity and stability under basic conditions. The TOF and FE values after $2 \mathrm{~h}$ electrolysis at $\eta=390 \mathrm{mV}$ for FTO $\mid \mathrm{CoS}$, FTO $|\mathrm{Co}, \mathrm{FTO}| \mathrm{Co}(\mathrm{OH})_{2}, \mathrm{FTO} \mid \mathrm{Co}_{3} \mathrm{O}_{4}$, and $\mathrm{FTO} \mid \mathrm{Co}_{9} \mathrm{~S}_{8}$ are given in Table 1 . In addition, when the electrolysis at $\eta=$ $390 \mathrm{mV}$ was extended to $72 \mathrm{~h}$ (Fig. $\mathrm{S} 4 \dagger$ ), a TON of more than 3400 with an FE of $94.1 \pm 4.8 \%$ demonstrates that $\operatorname{CoS}$ is an
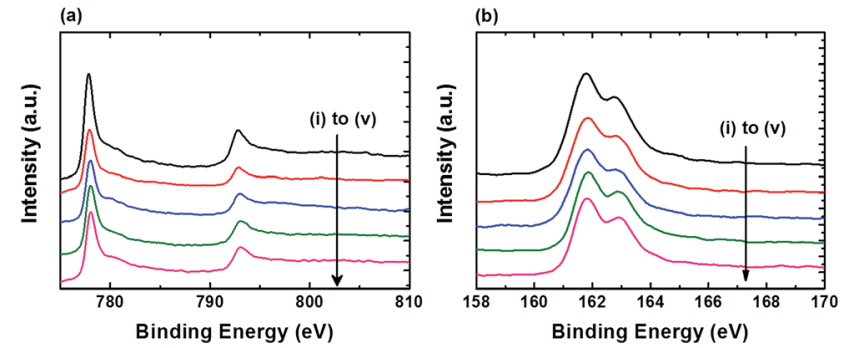

Fig. 2 XPS spectra of FTO|CoS before electrolysis (i), and after $2 \mathrm{~h}$ electrolysis at (ii) $\eta=90 \mathrm{mV}$, (iii) $\eta=190 \mathrm{mV}$, (iv) $\eta=290 \mathrm{mV}$, (v) $\eta=$ $390 \mathrm{mV}$ in $\mathrm{pH}$ neutral solution ( $\mathrm{pH}$ 7) containing TEOA $(50 \mathrm{mM})$ and $\mathrm{Na}_{2} \mathrm{SO}_{4}(0.1 \mathrm{M}$ ). (a) Co $2 \mathrm{p}$ region. (b) $\mathrm{S} 2 \mathrm{p}$ region. 
efficient and robust catalyst for HER not only in $\mathrm{pH}$ neutral, but also in strongly alkaline conditions, where many other state-ofthe-art catalysts such as $\mathrm{MoS}_{x}$ are not stable. ${ }^{5}$

CoS shows enhanced HER activity in phosphate buffer (Fig. S6†), ${ }^{23}$ but we note that employing CoS in phosphate buffer (0.5 M, pH 7) results in the conversion of CoS into a cobalt hydroxide phosphate species with $\mathrm{P} / \mathrm{Co} / \mathrm{O}$ ratio of $1: 0.99: 9.79$ (Fig. S6 $\dagger$ ). A high HER activity was also reported for $\operatorname{CoS}_{2}(\sim 4$ $\mathrm{mA} \mathrm{cm} \mathrm{cm}^{-2}$ at $\eta=225 \mathrm{mV}$ ) prepared from an expensive and energy-intensive e-beam evaporation and high temperature annealing process. ${ }^{13 b}$ However, HER activity of $\mathrm{CoS}_{2}$ was only examined under strongly acidic conditions (0.5 $\left.\mathrm{M} \mathrm{H}_{2} \mathrm{SO}_{4}\right)$. In this study, we prepared CoS by a simple and scalable CBD method, whereas the synthesis of other metal sulphides, such as $\mathrm{MoS}_{x}$ and $\mathrm{WS}_{x}$ typically requires an inert atmosphere, tedious, costly and/or energy intensive procedures. ${ }^{4 a, c-e, \boldsymbol{i}, \mathbf{1 2 , 1 3}}$ In addition, our studies show that $\mathrm{CoS}$ is highly active over a wide $\mathrm{pH}$ range ( $\mathrm{pH} 7$ and $\mathrm{pH}$ 13) with the cobalt sulphide structure remaining intact during the electrochemical experiments.

\section{Electroactivity of CoS microtube array}

We increased the surface roughness of CoS by micro-structuring to enhance the rate of HER per geometric area. An array of layered hydroxide cobalt carbonate acicular nanorods (FTO| nanoLHCC) was first grown onto an FTO substrate in water containing $\mathrm{CoCl}_{2}$ and urea at $90{ }^{\circ} \mathrm{C}$ for $4 \mathrm{~h}$, followed by its conversion into a CoS microtube array (FTO $\mid$ microCoS) via CBD at $90{ }^{\circ} \mathrm{C}$ for $6 \mathrm{~h}$ (see Experimental section). The conversion of FTO|nanoLHCC into FTO|microCoS was confirmed by XRD and XPS (Fig. S7 $\dagger$ ). As compared with the CoS thin film (Fig. S2a $\dagger$ ), nanoLHCC has a tubular structure and its diameter increases with prolonged reaction time (Fig. $3 \mathrm{a}$ and $\mathrm{b}$ and $\mathrm{S} 8 \dagger$ ), indicating the growth of a CoS layer on nanoLHCC. TEM images (Fig. S9†) confirm that nanoLHCC has a solid interior, but polycrystalline shells and voids form when the sulphurisation process started. A tubular structure is formed after $6 \mathrm{~h}$, which indicates the conversion process involves not only the deposition of CoS onto nanoLHCC from the reaction of $\mathrm{Co}^{2+}$ and $\mathrm{S}^{2-}$ ions in the bulk solution, but also the reaction of $\mathrm{Co}^{2+}$ ions inside nanoLHCC with $\mathrm{S}^{2-}$ ions close to the nanoLHCC|bath solution interface via the nanoscale Kirkendall effect. ${ }^{24}$

A possible mechanism for the formation of $\mathrm{CoS}$ microtubes is proposed as follows (Fig. 3c): first, $\mathrm{S}^{2-}$ ions are released into the bath solution upon decomposition of thioacetamide at 90 ${ }^{\circ} \mathrm{C}$ and react with $\mathrm{Co}^{2+}$ ions and nanoLHCC, resulting in the formation of a CoS shell. The higher diffusivity of cobalt ions than that of sulphide ions results in voids close to the interface, and the thickness of the CoS shell along with the number of voids in the core of the tube increases with reaction time. Finally, the voids connect to each other and form the tubular CoS structure as shown in the TEM images in Fig. 3c and S9. $\dagger$

The relative effective surface area between FTO|microCoS and FTO $\mid \mathrm{CoS}$ is determined by measuring double-layer capacitance using cyclic voltammetry. ${ }^{25}$ The results (Fig. S10†) reveal that the effective surface area, i.e., surface roughness, of FTO| microCoS is about 17 times higher than that of FTO|CoS. (a)
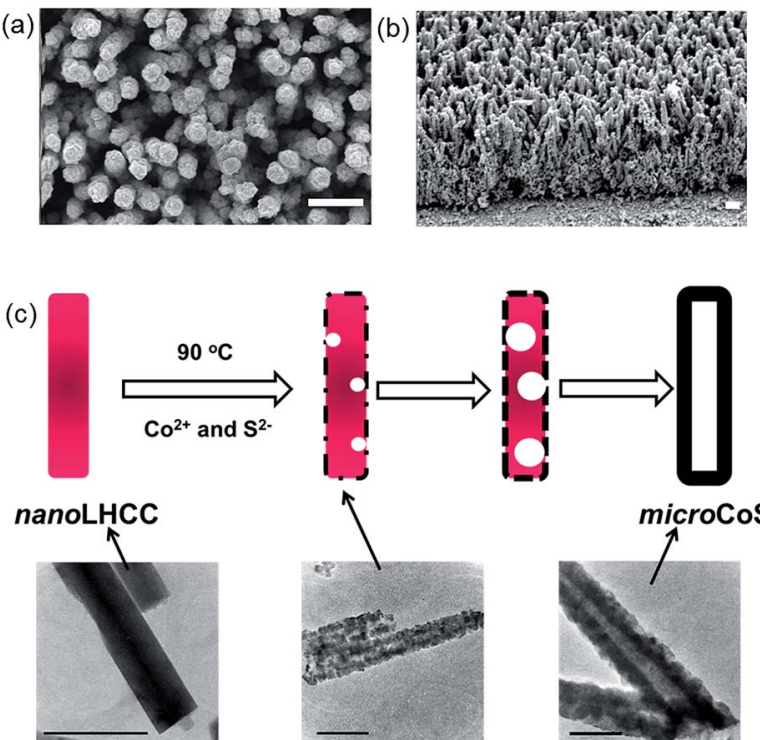

$(0 \mathrm{~h})$

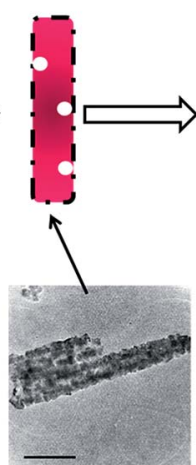

$(2 \mathrm{~h})$
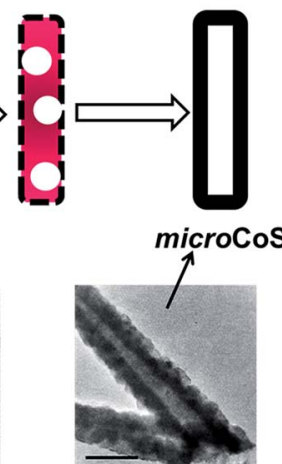

$(6 \mathrm{~h})$

Fig. 3 (a) Top-view and (b) tilted $\left(45^{\circ}\right)$ SEM images of FTO|microCoS after $6 \mathrm{~h}$ CBD sulphurisation of FTO|nanoLHCC. (c) Schematic illustration of the mechanism of microCoS formation with TEM images at different CBD sulphurisation stages (i.e., 0 h, 2 h, and 6 h, respectively). Scale bars in ( $a$ and $b$ ) and (c) are 1 and $0.5 \mu \mathrm{m}$, respectively.

Fig. S11† shows the LSVs of FTO|microCoS in a basic electrolyte solution ( $\mathrm{pH} 13)$ containing $\mathrm{KOH}(0.1 \mathrm{M})$ and $\mathrm{Na}_{2} \mathrm{SO}_{4}(0.1 \mathrm{M})$. It is found that the increased surface roughness indeed remarkably enhances the catalytic current per geometric area; FTO| microCoS shows a current density of $-0.44 \mathrm{~mA} \mathrm{~cm}{ }^{-2}$ at $\eta=$ $190 \mathrm{mV}$, which is about six times higher than FTO|CoS $\left(-0.08 \mathrm{~mA} \mathrm{~cm}^{-2}\right.$, Fig. S11a $\left.\dagger\right)$. However, the catalytic current of CoS does not scale proportionally with its surface area, i.e., the catalytic current density of FTO|microCoS is lower than that of FTO|CoS after normalisation with respect to the roughness factor (Fig. S11b $\dagger$ ), which can be attributed to the loss by (i) increasing $i-R$ drop with increasing current, and (ii) the semiconducting properties of $\mathrm{CoS}$ and the short charge carrier diffusion length in CoS. ${ }^{4 i}$ The same behaviour has also been observed in neutral electrolyte $(50 \mathrm{mM}$ TEOA and $0.1 \mathrm{M}$ $\mathrm{Na}_{2} \mathrm{SO}_{4}$ ), where the average current density of FTO|microCoS during 24 h electrolysis at $\eta=390 \mathrm{mV}$ is about $-2.7 \mathrm{~mA} \mathrm{~cm}^{-2}$, which is only about 2.25 times higher than that of FTO|CoS (see Fig. S5a and S12a †). We note that FTO|nanoLHCC is inactive towards HER (see Fig. S13 $\dagger$ ), and the maximal HER activity of FTO $\mid$ microCoS can therefore only be expected when nanoLHCC is completely converted into microCoS $(6 \mathrm{~h})$. FTO|microCoS also kept its crystalline structure after $24 \mathrm{~h}$ electrolysis as confirmed by XRD (Fig. S12b $\dagger$ ). Nevertheless, the excellent geometric catalytic current of microCoS motivated us to employ FTO| microCoS as a cathode in PEC water splitting, where the use of alkaline electrolyte is often indispensable.

\section{MicroCoS as cathode in PEC water splitting}

Hematite $\left(\alpha-\mathrm{Fe}_{2} \mathrm{O}_{3}\right)$, an earth-abundant and chemically stable semiconductor, has a bandgap of $2.2 \mathrm{eV}$ and a favourable 
valence band potential for water oxidation, which makes itself a promising photoanode material for PEC water oxidation..$^{2 e f, 26}$ The conduction band level of hematite is more positive than the potential of proton reduction, and an external bias is therefore required when it is combined with a $\mathrm{H}_{2}$ evolving cathode in a two-electrode PEC water splitting device. ${ }^{26}$ In addition, the use of a hematite photoanode requires an alkaline electrolyte solution, which in the past has limited the selection of cathode materials to noble metals such as Pt. ${ }^{2 e f f}$ Here, we demonstrate that FTO $\mid$ microCoS can be used as an inexpensive alternative to Pt in this hematite based PEC water splitting system. A tin doped hematite nanorod ( $\mathrm{FTO} \mid$ nano $\mathrm{Fe}_{2} \mathrm{O}_{3}$ ) photoanode is prepared by using a similar procedure reported previously (see Experimental section). ${ }^{27}$ Physical characterisations of FTO| nano $\mathrm{Fe}_{2} \mathrm{O}_{3}$ are shown in Fig. 4a and $\mathrm{S} 14 . \dagger \mathrm{FTO} \mid$ nanoFe $\mathrm{O}_{3}\left(2 \mathrm{~cm}^{2}\right)$ shows a photocurrent of approximately $0.6 \mathrm{~mA}$ at $1.23 \mathrm{~V} v$ s. RHE in a three-electrode, two compartment cell under standardised solar light irradiation (100 mW cm ${ }^{-2}$, AM 1.5G, Fig. 4b).

FTO| nano $\mathrm{Fe}_{2} \mathrm{O}_{3}$ was subsequently combined with a Pt or FTO|microCoS cathode $\left(2.5 \mathrm{~cm}^{2}\right)$ in a two-electrode twocompartment PEC cell. A photocurrent of 0.15 to $0.20 \mathrm{~mA}$ was obtained at an external bias of $1.23 \mathrm{~V}$ (Fig. 4c). Note that the separation between photoanode and cathode is approximately $10 \mathrm{~cm}$, and therefore, the loss in photocurrent by $i-R$ drop is expected to be significant. ${ }^{28}$ The amount of $\mathrm{H}_{2}$ and $\mathrm{O}_{2}$ detected from PEC water splitting after $2 \mathrm{~h}$ irradiation $\left(100 \mathrm{~mW} \mathrm{~cm}^{-2}\right.$, AM 1.5G) was (i) $4.3 \pm 0.4 \mu \mathrm{mol} \mathrm{H}_{2}$ and $2.3 \pm 0.4 \mu \mathrm{mol} \mathrm{O}_{2}$ with a (a)
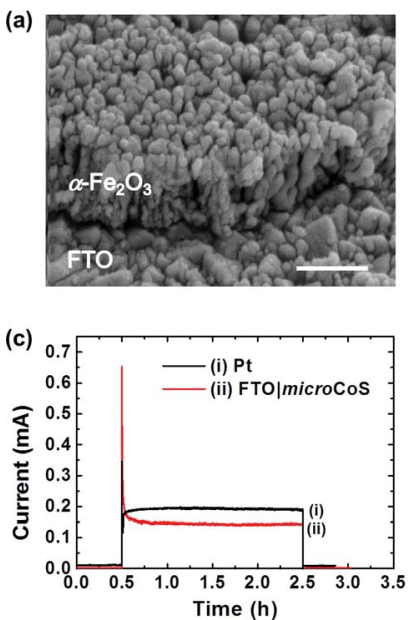

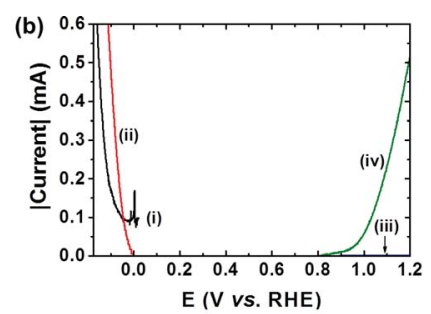

(d)

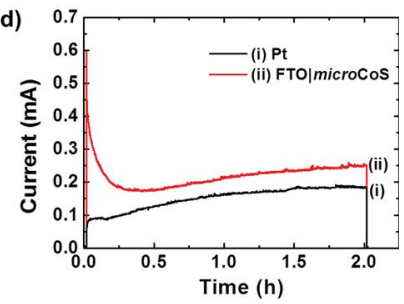

Fig. 4 (a) SEM image of FTO|nanoFe $\mathrm{O}_{3}$. Scale bar is $0.5 \mu \mathrm{m}$. (b) LSVs of FTOlmicroCoS (i, $\left.2.5 \mathrm{~cm}^{2}\right)$, Pt (ii, $2.5 \mathrm{~cm}^{2}$ ), and $\mathrm{FTO}$ nanoFe $\mathrm{O}_{3}(2.0$ $\mathrm{cm}^{2}$ ) in the dark (iii) and during irradiation (iv). LSVs for FTO|microCoS and $\mathrm{Pt}$ were recorded at $0.05 \mathrm{mV} \mathrm{s}^{-1}$, whereas LSVs for FTOl nanoFe $\mathrm{O}_{3}$ was recorded at $5 \mathrm{mV} \mathrm{s}^{-1}$. (c) Photocurrent transients of a two-electrode PEC cell with Pt or FTO|microCoS combined with FTOI nano $\mathrm{Fe}_{2} \mathrm{O}_{3}$ at $1.23 \mathrm{~V}$ bias under irradiation. The electrolyte used for $\mathrm{b}$ and $\mathrm{c}$ contains $\mathrm{KOH}(0.1 \mathrm{M})$ and $\mathrm{Na}_{2} \mathrm{SO}_{4}(0.1 \mathrm{M})$ at $\mathrm{pH}$ 13. (d) Photocurrent transients of a two-electrode PEC cell with Pt or FTO|micro$\mathrm{CoS}$ combined with $\mathrm{FTO} \mid$ nanoZnOlCdS $\mathrm{NP}_{\mathrm{NP}}$ at short-circuit condition under irradiation at $\mathrm{pH}$ 12.5. Light intensity: $100 \mathrm{~mW} \mathrm{~cm}^{-2}$ (AM 1.5G). MicroCoS in (b) shows a $80 \mu \mathrm{A}$ capacitive (non-Faradaic) current at $0 \mathrm{~V}$ vs. RHE in (curve i). The dark current shown in curve (ii) in (c) and (d) is negligible.
Pt foil and $2.7 \pm 0.2 \mu \mathrm{mol} \mathrm{H}_{2}$ and $1.9 \pm 0.2 \mu \mathrm{mol} \mathrm{O}_{2}$ with FTO| microCoS as cathode (Fig. S15†). FTO|microCoS therefore produces approximately $37 \%$ less $\mathrm{H}_{2}$ than Pt. The lower $\mathrm{H}_{2}$ production yield can be attributed to the additional $50 \mathrm{mV}$ overpotential requirement for FTO $\mid$ micro $\mathrm{CoS}$ to show comparable catalytic current with Pt (Fig. 4b). We note that there was no obvious change in surface morphology (SEM) and surface composition (XPS) of FTO $\mid$ nano $\mathrm{Fe}_{2} \mathrm{O}_{3}$ after $2 \mathrm{~h}$ PEC experiment, indicating $\mathrm{FTO} \mid$ nano $\mathrm{Fe}_{2} \mathrm{O}_{3}$ is stable during PEC conditions (Fig. S14e-i†).

Another demonstration (Fig. $4 \mathrm{~d}$ and S16†) of FTO|microCoS in $\mathrm{PEC} \mathrm{H}_{2}$ generation is its coupling with a cadmium sulphide (CdS) nanoparticle sensitised $\mathrm{ZnO}$ nanosheet photoanode (FTO| nanoZnO|CdS $_{\mathrm{NP}}$ ) in basic electrolyte (pH 12.5) containing TEOA $(50 \mathrm{mM})$ and $\mathrm{Na}_{2} \mathrm{~S}(0.1 \mathrm{M})$. CdS has received much attention due to its suitable bandgap $(\sim 2.4 \mathrm{eV})$ and favourable conduction band position $(-1.1 \mathrm{~V} \text { vs. NHE, } \mathrm{pH} 7)^{29}$ for $\mathrm{H}_{2}$ generation. However, the use of a hole scavenger, such as $\mathrm{Na}_{2} \mathrm{~S}$, is necessary to prevent CdS from photocorrosion by the photogenerated holes in CdS, which is the reason why there is no $\mathrm{O}_{2}$ evolution in this system. The physical characterisation of FTO| nanoZnO|CdS $\mathrm{CP}_{\mathrm{NP}}$ is shown in Fig. S16a-d. $\dagger$ The highly porous $\mathrm{ZnO}$ nanosheet architecture, which is prepared by growing layered zinc hydroxide carbonate using CBD, followed by thermal annealing, not only provides high surface area for $\mathrm{CdS}_{\mathrm{NP}}$ loading, but also facilitates the diffusion of the sacrificial hole scavenger, resulting in a high photocurrent response with good stability. Fig. 4d shows that the photocurrent response of the PEC cell with FTO|microCoS, operated at short-circuit condition as cathode is higher than that with $\mathrm{Pt}$ foil as cathode, which can be attributed in part to poisoning of Pt by sulphur species. ${ }^{30}$ After $2 \mathrm{~h}$ irradiation, the PEC cell with Pt as cathode generated $3.1 \pm 0.4 \mu \mathrm{mol} \mathrm{H}_{2}$, whereas FTO $\mid$ microCoS produced $4.0 \pm 0.9 \mu \mathrm{mol} \mathrm{H}_{2}$. As with FTO nano $_{2} \mathrm{O}_{3}$, SEM and XPS analysis of $\mathrm{FTO} \mid$ nano $\mathrm{ZnO} \mid \mathrm{CdS}_{\mathrm{NP}}$ showed no signs of changes in surface morphology and surface composition after $2 \mathrm{~h}$ PEC experiment (Fig. S16d-h†े).

\section{Conclusions}

In this study, CoS has been selected from a series of different Co species as the most active and as a robust material in catalysing HER under both neutral ( $\mathrm{pH} 7)$ and basic ( $\mathrm{pH} 13)$ aqueous conditions. The three-dimensional morphology of microtubular $\mathrm{CoS}$ can easily be prepared by CBD and microCoS displays a substantially enhanced catalytic current per geometric area for $\mathrm{H}_{2}$ generation compared to flat CoS films. The microCoS array was employed as efficient cathode in combination with photoanodes such as a nanostructured $\alpha-\mathrm{Fe}_{2} \mathrm{O}_{3}$ (hematite) photoanode, thereby allowing for water splitting in a PEC cell fully made of earth abundant elements.

\section{Acknowledgements}

Financial support from EPSRC (EP/H00338X/2 and Cambridge Centre for Doctoral Training in Sustainable and Functional Nano), the Christian Doppler Research Association (Austrian 
Federal Ministry of Science, Research and Economy, and National Foundation for Research, Technology and Development) and the OMV Group is gratefully acknowledged. We also thank the Ministry of Science and Technology, and Ministry of Education, Taiwan (102-2218-E-006-014-MY2 and the Aim for the Top University Project to National Cheng Kung University, respectively).

\section{References}

1 N. S. Lewis and D. G. Nocera, Proc. Natl. Acad. Sci. U. S. A., 2006, 103, 15729-15735.

2 (a) C.-Y. Lin, Y.-H. Lai, D. Mersch and E. Reisner, Chem. Sci., 2012, 3, 3482-3487; (b) J. Su, L. Guo, N. Bao and C. A. Grimes, Nano Lett., 2011, 11, 1928-1933; (c) Y. Lin, S. Zhou, S. W. Sheehan and D. Wang, J. Am. Chem. Soc., 2011, 133, 2398-2401; (d) G. K. Mor, O. K. Varghese, R. H. T. Wilke, S. Sharma, K. Shankar, T. J. Latempa, K.-S. Choi and C. A. Grimes, Nano Lett., 2008, 8, 19061911; (e) I. Cesar, A. Kay, J. A. G. Martinez and M. Grätzel, J. Am. Chem. Soc., 2006, 128, 4582-4583; $(f)$ K. Sivula, R. Zboril, F. Le Formal, R. Robert, A. Weidenkaff, J. Tucek, J. Frydrych and M. Grätzel, J. Am. Chem. Soc., 2010, 132, 7436-7444.

3 (a) J. A. Seabold and K.-S. Choi, J. Am. Chem. Soc., 2012, 134, 2186-2192; (b) M. Dincă, Y. Surendranath and D. G. Nocera, Proc. Natl. Acad. Sci. U. S. A., 2010, 107, 10337-10341; (c) M. W. Kanan and D. G. Nocera, Science, 2008, 321, 1072-1075; (d) G. L. Elizarova, G. M. Zhidomirov and V. N. Parmon, Catal. Today, 2000, 58, 71-88; (e) R. E. Rocheleau, E. L. Miller and A. Misra, Energy Fuels, 1998, 12, 3-10; $(f)$ Y.-H. Lai, T. C. King, D. S. Wright and E. Reisner, Chem. - Eur. J., 2013, 19, 12943-12947.

4 (a) H. Vrubel, D. Merki and X. Hu, Energy Environ. Sci., 2012, 5, 6136-6144; (b) J. Kibsgaard, Z. Chen, B. N. Reinecke and T. F. Jaramillo, Nat. Mater., 2012, 11, 963-969; (c) D. Merki, S. Fierro, H. Vrubel and X. Hu, Chem. Sci., 2011, 2, 12621267; (d) J. Bonde, P. G. Moses, T. F. Jaramillo, J. K. Nørskov and I. Chorkendorff, Faraday Discuss., 2008, 140, 219-231; (e) T. F. Jaramillo, K. P. Jørgensen, J. Bonde, J. H. Nielsen, S. Horch and I. Chorkendorff, Science, 2007, 317, 100-102; (f) W.-F. Chen, K. Sasaki, C. Ma, A. I. Frenkel, N. Marinkovic, J. T. Muckerman, Y. Zhu and R. R. Adzic, Angew. Chem., Int. Ed., 2012, 51, 6131-6135; (g) M. L. Helm, M. P. Stewart, R. M. Bullock, M. Rakowski DuBois and D. L. DuBois, Science, 2011, 333, 863-866; (h) Y. Hou, B. L. Abrams, P. C. K. Vesborg, M. E. Björketun, K. Herbst, L. Bech, A. M. Setti, C. D. Damsgaard, T. Pedersen, O. Hansen, J. Rossmeisl, S. Dahl, J. K. Nørskov and I. Chorkendorff, Nat. Mater., 2011, 10, 434-438; (i) D. Voiry, H. Yamaguchi, J. Li, R. Silva, D. C. B. Alves, T. Fujita, M. Chen, T. Asefa, V. B. Shenoy, G. Eda and M. Chhowalla, Nat. Mater., 2013, 12, 850-855.

5 H. Vrubel and X. Hu, Angew. Chem., Int. Ed., 2012, 51, 1270312706.
6 P. D. Tran, L. Xi, S. K. Batabyal, L. H. Wong, J. Barber and J. S. C. Loo, Phys. Chem. Chem. Phys., 2012, 14, 11596-11599. 7 (a) N. M. Muresan, J. Willkomm, D. Mersch, Y. Vaynzof and E. Reisner, Angew. Chem., Int. Ed., 2012, 51, 12749-12753; (b) E. S. Andreiadis, P.-A. Jacques, P. D. Tran, A. Leyris, M. Chavarot-Kerlidou, B. Jousselme, M. Matheron, J. Pécaut, S. Palacin, M. Fontecave and V. Artero, Nat. Chem., 2013, 5, 48-53.

8 S. Cobo, J. Heidkamp, P.-A. Jacques, J. Fize, V. Fourmond, L. Guetaz, B. Jousselme, V. Ivanova, H. Dau, S. Palacin, M. Fontecave and V. Artero, Nat. Mater., 2012, 11, 802-807.

9 C.-W. Kung, H.-W. Chen, C.-Y. Lin, K.-C. Huang, R. Vittal and K.-C. Ho, ACS Nano, 2012, 6, 7016-7025.

10 Z. Yang, C.-Y. Chen, C.-W. Liu and H.-T. Chang, Chem. Commun., 2010, 46, 5485-5487.

11 S. M. Ahmed, Int. J. Miner. Process., 1978, 5, 163-174.

12 P. D. Tran, M. Nguyen, S. S. Pramana, A. Bhattacharjee, S. Y. Chiam, J. Fize, M. J. Field, V. Artero, L. H. Wong, J. Loo and J. Barber, Energy Environ. Sci., 2012, 5, 89128916.

13 (a) D. Merki, H. Vrubel, L. Rovelli, S. Fierro and X. Hu, Chem. Sci., 2012, 3, 2515-2525; (b) D. Kong, J. J. Cha, H. Wang, H. R. Lee and Y. Cui, Energy Environ. Sci., 2013, 6, 3553-3558. 14 C. Q. Cui, S. P. Jiang and A. C. C. Tseung, J. Electrochem. Soc., 1990, 137, 3418-3423.

15 C.-W. Kung, C.-Y. Lin, Y.-H. Lai, R. Vittal and K. C. Ho, Biosens. Bioelectron., 2011, 27, 125-131.

16 C.-Y. Lin, Y.-H. Lai, H.-W. Chen, J.-G. Chen, C.-W. Kung, R. Vittal and K.-C. Ho, Energy Environ. Sci., 2011, 4, 34483455.

17 E. D. Spoerke, M. T. Lloyd, Y.-j. Lee, T. N. Lambert, B. B. McKenzie, Y.-B. Jiang, D. C. Olson, T. L. Sounart, J. W. P. Hsu and J. A. Voigt, J. Phys. Chem. C, 2009, 113, 16329-16336.

18 L. Xi, S. Y. Chiam, W. F. Mak, P. D. Tran, J. Barber, S. C. J. Loo and L. H. Wong, Chem. Sci., 2013, 4, 164-169.

19 (a) A. Galtayries and J. Grimblot, J. Electron Spectrosc. Relat. Phenom., 1999, 98-99, 267-275; (b) T. Baird, K. C. Campbell, P. J. Holliman, R. W. Hoyle, M. Huxam, D. Stirling, B. P. Williams and M. Morris, J. Mater. Chem., 1999, 9, 599-605.

20 M. Pourbaix, Atlas of electrochemical equilibria in aqueous solutions, National Association of Corrosion Engineers, Huston, TX, 1974, pp. 324-325.

21 G. Valiulienè, A. Žielienè and J. Vinkevičius, J. Solid State Electrochem., 2002, 6, 396-402.

22 P. Elumalai, H. N. Vasan and N. Munichandraiah, J. Power Sources, 2001, 93, 201-208.

23 Y. Sun, C. Liu, D. C. Grauer, J. Yano, J. R. Long, P. Yang and C. J. Chang, J. Am. Chem. Soc., 2013, 135, 17699-17702.

24 Y. Yin, R. M. Rioux, C. K. Erdonmez, S. Hughes, G. A. Somorjai and A. P. Alivisatos, Science, 2004, 304, 711714.

25 S. Trasatti and O. A. Petrii, Pure Appl. Chem., 1991, 63, 711734.

26 R. L. Spray, K. J. McDonald and K.-S. Choi, J. Phys. Chem. C, 2011, 115, 3497-3506. 
27 L. Xi, S. Y. Chiam, W. F. Mak, P. D. Tran, J. Barber, S. C. J. Loo and L. H. Wong, Chem. Sci., 2013, 4, 164-169.

28 E. A. Hernández-Pagán, N. M. Vargas-Barbosa, T. Wang, Y. Zhao, E. S. Smotkin and T. E. Mallouk, Energy Environ. Sci., 2012, 5, 7582-7589.
29 J. Ran, J. Yu and M. Jaroniec, Green Chem., 2011, 13, 27082713.

30 V. A. Sethuraman and J. W. Weidner, Electrochim. Acta, 2010, 55, 5683-5694. 